\title{
A Reliability Impact and Assessment of Distributed Generation Integration to Distribution System
}

\author{
Atthapol Ngaopitakkul $^{1}$, Chaichan Pothisarn ${ }^{1}$, Sulee Bunjongjit ${ }^{1}$, Boonlert Suechoey $^{2}$, \\ Chaiyo Thammart ${ }^{2}$, Auttarat Nawikavatan ${ }^{2}$ \\ ${ }^{1}$ Department of Electrical Engineering, Faculty of Engineering, King Mongkut's Institute of Technology Ladkrabang, \\ Bangkok, Thailand \\ ${ }^{2}$ Department of Electrical Engineering, Faculty of Engineering, South-East Asia University, Bangkok, Thailand \\ Email: knatthap@kmitl.ac.th
}

Received April, 2013

\begin{abstract}
The main purpose of this paper is to study the reliability due to the employment of distributed generations (DG) integrated to distribution system. The system under this study is from Provincial Electricity Authority (PEA) that is a part of Thailand's distribution system. Data of geographic information systems (GIS) including the distance of distribution line and location of load that are parameter of PEA is simulated using digital simulation and electrical network calculation program (DIgSILENT) to analyze the impact of reliability with the installing DG into the distribution system. The system average interruption frequency index (SAIFI), the system average interruption duration index (SAIDI) and interruption cost are assessed as index of reliability by comparing the SAIFI, SAIDI, and interruption cost between the base case (no DG) and the case that DG connected to the distribution system. The results can be summarized by focusing on location of DG, the capacity of DG, the size of load, and the distance of load which are factors able to impact to SAIFI, SAIDI, and interruption cost.
\end{abstract}

Keywords: Reliability; Distributed Generation; Interruption Cost; Distribution System; SAIFI; SAIDI

\section{Introduction}

Nowadays, the distributed generation (DG) is connected into the distribution system; there are many issues [1-10] that may cause the technical impacts to the distribution system. Reliability is one of problems that are interested based on studies research papers related to this subject. In the literature [1,2], this paper proposed a method to analyze and evaluate the reliability of the transmission equipment in the electrical system when installing the generator to a distributed system as a case study. The value of the damage (Failure Rates) is calculated in [3-8] which analyzes and compares the reliability of the power system in the different case studies. In the literature [9, 10], the authors use a Monte Carlo Simulation to random the location of generator in distributed system, and then determine the reliability of the power system.

The paper mainly focuses on analyzing and evaluating the reliability in order to improve the reliability of power system but not for analyzing in terms of the interruption cost in case of power failure. This paper studies the impact of reliability when a distributed generator (DG) is installed into the distribution system. The system under this study is from Provincial Electricity Authority (PEA) that is a part of Thailand's distribution system. DIgSILENT power factory is employed to simulate and analyse the SAIFI, SAIDI and interruption cost when distributed generation (DG) is connected to $22 \mathrm{kV}$ distribution system.

\section{Distribution Reliability Indices}

Because of customer satisfaction, the utility of individual customers to get the best service with the least amount of power failure is important. The majority of customer reliability problem is caused by distribution system. Utilities often monitor the reliability of customers by using a reliability index. Therefore, calculating the reliability index is interesting for their customers. The use of index to indicate the average number of times of the power failure and power outage per year per one customer makes it possible to compare between different systems and can also be targeted. The most common customer reliability indices are:

System Average Interruption Frequency Index (SAIFI)

$$
\mathrm{ASIFI}=\frac{\sum_{i}^{\lambda} N_{i}}{\sum N_{i}}
$$


System Average Interruption Duration Index (SAIDI)

$$
\text { SAIDI }=\frac{\sum U_{i} N_{i}}{\sum N_{i}}
$$

Interruption Cost

$$
\operatorname{ECOST}=\sum_{h=1}^{n h} \sum_{k=1}^{n k} L_{k} C_{h k}\left(r_{h}\right) \lambda
$$

where,

$\lambda_{i}$ is the failure rate or interruption events

$\mathrm{N}_{\mathrm{i}}$ is the number of customers served of node $\mathrm{i}$

$\mathrm{U}_{\mathrm{i}}$ is the restoration time or customer interruption durations of node $i$

$\mathrm{n}_{\mathrm{k}}$ is the total number of load points in the study area

$n_{h}$ is the total number of outages that lead to power interruption at load point $\mathrm{k}$

$\mathrm{L}_{\mathrm{k}}$ is the magnitude of the load curtailed in MW at load point $\mathrm{k}$

$r_{h}$ is duration of the contingency $h$

$\mathrm{C}_{\mathrm{hk}}$ is the cost of an outage contingency of duration $\mathrm{r}_{\mathrm{h}}$

$\lambda_{\mathrm{h}}$ is the failure rate of the equipment

\section{Power System Simulation using DIgSILENT}

The scheme under investigation is part of Thailand's electricity distribution system. DIgSILENT powerfactory is employed to simulate and analyse the reliability when distributed generation (DG) is connected to $22 \mathrm{kV}$ distribution systems as shown in Figure 1. Data of geographic information systems (GIS) including the distance of distribution line and location of load that are parameter of PEA are shown in Table 1.

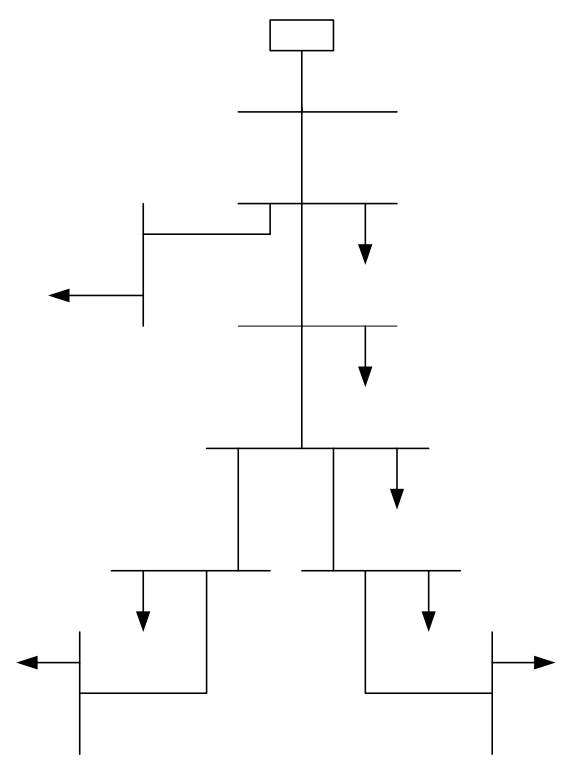

Figure 1. A simple radial system with DG connected.
Table 1. The length of transmission line and load in each bus which is connected in distribution system.

\begin{tabular}{ccc}
\hline Bus & Distance $(\mathrm{km})$ & Load $(\mathrm{MW})$ \\
\hline Substation and & 4.4 & 0.14 \\
1 and 2 & 16.6 & 2.47 \\
1 and 3 & 13 & 1.11 \\
2 and 4 & 28.5 & 1.35 \\
4 and 5 & 16.87 & 1.42 \\
4 and 6 & 18 & 0.62 \\
5 and 7 & 10 & 0.58 \\
6 and 8 & 18.52 & 0.69 \\
\hline
\end{tabular}

From Figure 1, it can be seen that there are 8 buses from substation (Sub_Chokchai) and load of each bus that is connected between distribution lines. To study the reliability, simulations were performed with various changes as follows:

- A number of distributed generators are no DG and with DG.

- The location of distributed generators are designated on any bus of distribution system and installed between buses of distribution system.

- The capacity of DG is 2 MVA, 4 MVA, 6 MVA, and 8 MVA installed at the distribution system.

\section{Impact of DG for Reliability}

The objective of this paper is to study the impact of reliability when distributed generation is connected to distribution system. The impact of DG is divided into 3 indices in order to evaluate the reliability of system. The SAIFI, SAIDI and Interruption cost of the base case (no DG) and with DG is compared. The results are shown in Table 2 and Table 3.

The first index, the SAIFI of base case (no DG) is 16.7464 times/customer/year while the SAIFI of PEA regulation must be changed lower than 17.34 times/customer/year. So the SAIFI will be compared with DG at each bus as shown in Table 2. The results shown that, when location of DG is considered by installing at bus 1 , 2 and 3, the SAIFI is equal to the case of the base case (no DG). Likewise, when the DG is installed at bus 4, bus 5 , bus 6 , bus 7 , and bus 8 , it can be seen that the SAIFI decreases. This indicates that utility has benefit from employing DG.

In addition, when capacity of DG is considered with 2 MVA, 4 MVA, 6 MVA and 8 MVA that is installed at each bus, the SAIFI is lower than the base case (no DG) except for the case that the capacity of DG is $8 \mathrm{MW}$ and installation location is at bus 5 and bus 7. It is noticed that, when the capacity of DG is increased, SAIFI tends to decrease so reliability of distribution system will be 
improved. This also indicates that capacity of DG and location of DG play an important role for reliability in such a system.

Table 2. The reliability index in case of DG installed at any buses of distribution system.

\begin{tabular}{|c|c|c|c|}
\hline Case & $\begin{array}{c}\text { SAIFI } \\
\text { (times/year) }\end{array}$ & $\begin{array}{c}\text { SAIDI } \\
\text { (hour/year) }\end{array}$ & $\begin{array}{c}\text { Interruption } \\
\text { Cost }(\$)\end{array}$ \\
\hline no DG & 16.7464 & 21.064 & 147,351 \\
\hline \multicolumn{4}{|c|}{ Bus 1} \\
\hline 2 MVA & 16.7464 & 21.055 & 150,904 \\
\hline 4 MVA & 16.7464 & 21.05 & 148,641 \\
\hline $6 \mathrm{MVA}$ & 16.7467 & 21.044 & 150,863 \\
\hline 8 MVA & 16.7462 & 21.039 & 148,608 \\
\hline \multicolumn{4}{|c|}{ Bus 2} \\
\hline 2 MVA & 16.7464 & 20.104 & 161,765 \\
\hline 4 MVA & 16.7464 & 19.316 & 149,031 \\
\hline $6 \mathrm{MVA}$ & 16.7464 & 18.52 & 156,261 \\
\hline 8 MVA & 16.7462 & 18.233 & 137,887 \\
\hline \multicolumn{4}{|c|}{ Bus 3} \\
\hline $2 \mathrm{MVA}$ & 16.7464 & 21.055 & 147,958 \\
\hline 4 MVA & 16.764 & 21.05 & 147,819 \\
\hline 6 MVA & 16.7464 & 21.044 & 148,095 \\
\hline 8 MVA & 16.7462 & 21.039 & 147,595 \\
\hline \multicolumn{4}{|c|}{ Bus 4} \\
\hline 2 MVA & 16.7464 & 19.629 & 157,973 \\
\hline 4 MVA & 12.15112 & 12.412 & 105,919 \\
\hline 6 MVA & 12.15112 & 11.776 & 103,279 \\
\hline 8 MVA & 12.15094 & 11.582 & 94,909 \\
\hline \multicolumn{4}{|c|}{ Bus 5} \\
\hline 2 MVA & 15.137 & 18.29 & 143,088 \\
\hline 4 MVA & 10.2316 & 10.763 & 90,727 \\
\hline $6 \mathrm{MVA}$ & 10.1089 & 10.217 & 87,322 \\
\hline 8 MVA & 29.6436 & 35.897 & 287,294 \\
\hline \multicolumn{4}{|c|}{ Bus 6} \\
\hline 2 MVA & 15.5458 & 18.69 & 148,283 \\
\hline 4 MVA & 10.9371 & 11.529 & 98,434 \\
\hline 6 MVA & 10.9371 & 10.494 & 95,722 \\
\hline 8 MVA & 10.9369 & 10.722 & 87,345 \\
\hline \multicolumn{4}{|c|}{ Bus 7} \\
\hline 2 MVA & 15.1368 & 18.315 & 143,182 \\
\hline 4 MVA & 9.6705 & 10.03 & 83,771 \\
\hline 6 MVA & 9.5021 & 9.695 & 80,711 \\
\hline 8 MVA & 29.1259 & 35.202 & 293,903 \\
\hline \multicolumn{4}{|c|}{ Bus 8} \\
\hline 2 MVA & 15.5457 & 18.699 & 148,379 \\
\hline 4 MVA & 10.3671 & 10.831 & 90,350 \\
\hline $6 \mathrm{MVA}$ & 10.3677 & 10.505 & 88,827 \\
\hline 8 MVA & 10.3677 & 10.303 & 83,115 \\
\hline
\end{tabular}

Table 3. The reliability index in case of DG that is installed between buses of distribution system.

\begin{tabular}{|c|c|c|c|}
\hline Case & $\begin{array}{c}\text { SAIFI } \\
\text { (times/year) }\end{array}$ & $\begin{array}{c}\text { SAIDI } \\
\text { (hour/year) }\end{array}$ & $\begin{array}{c}\text { Interruption } \\
\text { Cost }(\$)\end{array}$ \\
\hline no DG & 16.7464 & 21.064 & 147,351 \\
\hline \multicolumn{4}{|c|}{ Bus 1 - Bus 2} \\
\hline 2 MVA & 16.7464 & 20.087 & 163,000 \\
\hline 4 MVA & 16.7464 & 19.316 & 160,038 \\
\hline $6 \mathrm{MVA}$ & 16.7464 & 18.545 & 156,858 \\
\hline 8 MVA & 16.7462 & 18.233 & 138,892 \\
\hline \multicolumn{4}{|c|}{ Bus 1 - Bus 3} \\
\hline 2 MVA & 16.7464 & 21.055 & 147,881 \\
\hline 4 MVA & 16.7464 & 21.05 & 147,760 \\
\hline 6 MVA & 16.7464 & 21.044 & 148,122 \\
\hline 8 MVA & 16.7462 & 21.039 & 147,536 \\
\hline \multicolumn{4}{|c|}{ Bus 2 - Bus 4} \\
\hline 2 MVA & 16.7464 & 21.064 & 150,918 \\
\hline 4 MVA & 13.1397 & 15.377 & 119,819 \\
\hline $6 \mathrm{MVA}$ & 12.4914 & 14.301 & 112,710 \\
\hline 8 MVA & 12.1509 & 13.845 & 102,520 \\
\hline \multicolumn{4}{|c|}{ Bus 4 - Bus 5} \\
\hline 2 MVA & 16.7464 & 19.633 & 158,115 \\
\hline 4 MVA & 12.1511 & 12.4 & 106,089 \\
\hline $6 \mathrm{MVA}$ & 12.511 & 11.795 & 103,250 \\
\hline 8 MVA & 12.509 & 11.582 & 94,909 \\
\hline \multicolumn{4}{|c|}{ Bus 4 - Bus 6} \\
\hline 2 MVA & 15.5458 & 18.689 & 148,267 \\
\hline 4 MVA & 10.9506 & 11.557 & 98,669 \\
\hline $6 \mathrm{MVA}$ & 10.9505 & 10.95 & 95,723 \\
\hline 8 MVA & 10.9504 & 10.729 & 87,430 \\
\hline \multicolumn{4}{|c|}{ Bus 5 - Bus 7} \\
\hline 2 MVA & 15.1368 & 18.301 & 143,122 \\
\hline 4 MVA & 10.4714 & 11.081 & 92,509 \\
\hline 6 MVA & 10.0205 & 10.181 & 86,285 \\
\hline 8 MVA & 35.624 & 44.109 & 352,909 \\
\hline \multicolumn{4}{|c|}{ Bus 6 - Bus 8} \\
\hline 2 MVA & 15.5458 & 18.695 & 148,322 \\
\hline 4 MVA & 10.937 & 11.522 & 98,166 \\
\hline 6 MVA & 10.8112 & 10.88 & 94,342 \\
\hline 8 MVA & 10.5175 & 10.413 & 84,228 \\
\hline
\end{tabular}

The second index, the SAIDI of base case (no DG) is 21.064 hour/customer/year while the SAIDI of PEA regulation must be changed lower than 19.55 hour/cus -tomer/year. Similarly, capacity of DG and location of DG is considered so the behavior of SAIDI is shown in Table 2. The results show that, when location of DG is considered by installing at bus 1,2 and 3, the SAIDI is equal to the case of the base case (no DG). Likewise, when the DG is installed at bus 4 , bus 5 , bus 6 , bus 7 and bus 8 , it can be seen that the SAIDI is also decreased as 
same as SAIFI. This indicates that utility has still benefit from employing DG.

The capacity of DG is also considered; it is noticed that when the capacity of DG is increased, SAIDI tends to decrease as same as SAIFI. This also indicates that capacity of DG, location of DG, location of load, and size of load play an important role for reliability.

The third index, the interruption cost of base case (no DG) is 147,351 U.S. Dollar /year. Similarly, capacity of DG and location of DG are also considered; the obtained results for interruption cost are given in Table 2.

The results show that, when capacity of DG and location of DG is considered by installing at bus 1 to bus 3 , the interruption cost is increased and more than the base case (no DG) due that the size of load is large so average hours service availability of customer is decreased and the failure rate of the equipment $(\lambda)$ in equation 3 will be increased. Likewise, when the DG is installed at bus 4 , bus 5 , bus 6 , bus 7 and bus 8 , it can be seen that the interruption cost is decreased except for the capacity of DG is less than 2 MVA. This also indicates the slight mismatch between DG capacity and size of load. It is clearly seen for the cases that, when interruption cost is considered and the capacity of DG is 8 MVA which is installed at bus 7 and the size of load is $0.58 \mathrm{MW}$, the interruption cost is significantly increased.

From Table 3, it can be seen that the reliability index obtained from the base case as same as case of DG is installed on any bus will be compared with DG that is installed between bus. The first index, the SAIFI of base case (no DG) is still 16.746 times/customer/year and the SAIFI of PEA regulation is also 17.34 times/customer/ year. The results show that, when location of DG is considered by installing between bus 1-bus 2, bus 1-bus 3, the SAIFI is equal to the base case (no DG) and case of DG installed on any bus. Likewise, when the other case of DG in Table 3 is considered, it can be seen that the SAIFI is decreased and less than the base case but has value nearby the case of DG installed on any bus for the most cases except for the case that the capacity of DG is $8 \mathrm{MW}$ and DG location is between bus5-bus 7 with load of $0.58 \mathrm{MW}$. This also indicates that capacity of DG, location of DG, location of load, and size of load play an important role for reliability.

The second index, the SAIDI of base case (no DG) is still 21.064 hour/customer/year while the SAIDI of PEA regulation is also 19.55 hour/customer/year. Similarly, capacity of DG and location of DG are considered and the behavior of SAIDI is shown in Table 3. The results show that, when location of DG is considered and installed at bus 1,2 and 3, the SAIDI is equal to that of the base case (no DG). Likewise, when the DG is installed at bus 4 , bus 5 , bus 6 , bus 7 and bus 8 , it can be seen that the SAIDI is also decreased as same as SAIFI. This indi- cates that utility has still benefit from employing DG. In addition, when capacity of DG is considered, it is noticed that when the capacity of DG is increased, SAIDI tends to decrease as same as SAIFI.

The third index, the interruption cost of base case (no DG) is still 147,351 U.S. Dollar/year. Similarly, capacity of DG and location of DG are also considered and the obtained results from interruption cost are shown in Table 3 . The results show that, the interruption cost tends to decrease as same as the case of DG installed at bus. However, when the interruption cost is compared between DG installed at bus and installed between buses, it can be seen that the interruption cost of DG installed between buses is lower than that of the DG installed at bus. This also indicates the slight mismatch between DG location and size of load.

\section{Conclusions}

This paper focuses on the analysis of reliability with the inclusion of DG. The system average interruption frequency index (SAIFI), the system average interruption duration index (SAIDI), and interruption cost are assessed as index of reliability by comparing the SAIFI, SAIDI, and interruption cost between the base case (no DG) and the case that DG connected to the distribution system. The results can be summarized by focusing on the location of DG, the capacity of DG, the size of load, and the distance of load which are factors able to impact to SAIFI, SAIDI, and interruption cost as shown in Tables 2-3. Both the location of DG and the capacity of DG must take into account to reach optimal condition in order to create the suitability and fairness for both utility and DG.

\section{Acknowledgements}

The authors wish to gratefully acknowledge financial support for this research from the King Mongkut's Institute of Technology Ladkrabang Research Fund, Thailand and the energy policy and planning office (EPPO), Ministry of Energy, Thailand. They would like also to thank for the DIgSILENT presented in this paper which is supported by Provincial Electricity Authority (PEA).

\section{REFERENCES}

[1] M. Fotuhi-Firuzabad, "An Analytical Method to Consider DG Impacts on Distribution System Reliability," IEEE/PES Transmission and Distribution Conference and Exhibition: Asia and Pacific, 2005, pp. 1-6.

[2] I. K. Tarsi, A. Sheikholeslami, T. Barforoushi and S. M. B. Sadati, "Investigating Impacts of Distributed Generation on Distribution Networks Reliability: A Mathematical Model," Electric Power Quality and Supply Reliability Conference (PQ), 2010, pp.117-124. 
[3] H. Falaghi and M. Haghifam, "Distributed Generation Impacts on Electric Distribution Systems Reliability: Sensitivity Analysis," The International Conference on Computer as a Tool (EUROCON), Vol. 2, 2005, pp. 1465-1468.

[4] Y. Yue, K. J. Qian and C. K. Zhou, "The Effect of Distributed Generation on Distribution System Reliability," $42^{\text {nd }}$ International Universities Power Engineering Conference (UPEC), 2007, pp. 911-916.

[5] S. X. Wang, W. Zhao and Y. Y. Chen, "Distribution System Reliability Evaluation Considering DG Impacts," Third International Conference on Electric Utility Deregulation and Restructuring and Power Technologies (DRPT), 6-9 April 2008, pp. 2603-2607. doi:10.1109/DRPT.2008.4523850

[6] N. Chaiyabut and P. Damrongkulkamjorn, "Impact of Customer Scattering on Distribution System Reliability with Distributed Generation," IEEE Region 10 Conference (TENCON), 2010, pp. 568-573.
[7] A. C. Neto and M. G. da Silva, "Impact of Distributed Generation on Reliability Evaluation of Radial Distribution Systems Under Network Constraints," 9th International Conference on Probabilistic Methods Applied to Power Systems (PMAPS), 11-15 June 2006, pp. 1-6. doi:10.1109/PMAPS.2006.360421

[8] A. A. Chowdhury, "Reliability Modeling of Distributed Generation in Conventional Distribution Systems Planning and Analysis," IEEE Transactions on Industry Application, Vol. 39, No. 5, 2003, pp. 1493-1498. doi:10.1109/TIA.2003.816554

[9] In-Su Bae and Jin-O Kim, "Reliability Evaluation of Distributed Generation Based on Operation Mode," IEEE Transactions on Power Systems, Vol. 22, No. 2, 2007, pp. 785-790. doi:10.1109/TPWRS.2007.894842

[10] A. M. Abdullah, "New Method for Assessment of Distributed Generation Impact on Distribution System Reliability: Islanded Operation," IEEE Innovative Smart Grid Technologies - Asia (ISGT Asia), 2012, pp. 1-5. 